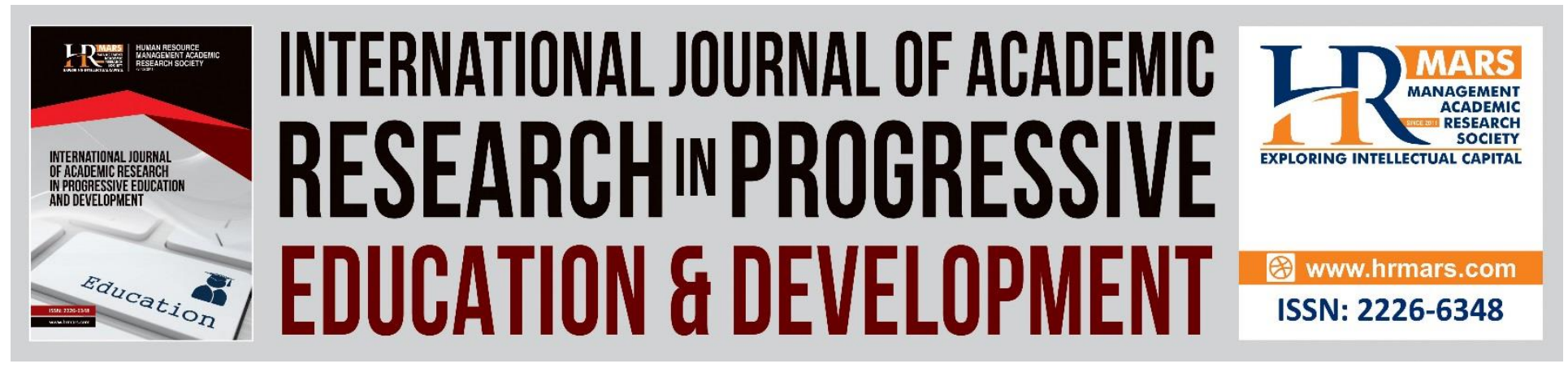

\title{
Potential Factors of Presenteeism: Job Demands, Work Engagement \& Job Insecurity
}

Daniella M. Mokhtar, Mohd Syazwan Zainal, Mohd Haikal Anuar Adnan

To Link this Article: http://dx.doi.org/10.6007/IJARPED/v8-i4/6780

DOI:10.6007/IJARPED/v8-i4/6780

Received: 23 October 2019, Revised: 28 November 2019, Accepted: 13 December 2019

Published Online: 28 December 2019

In-Text Citation: (Mokhtar et al., 2019)

To Cite this Article: Mokhtar, D. M., Zainal, M. S., \& Adnan, M. H. A. (2019). Potential Factors of Presenteeism: Job Demands, Work Engagement \& Job Insecurity. International Journal of Academic Research in Progressive Education and Development, 8(4), 900-911.

Copyright: (C) 2019 The Author(s)

Published by Human Resource Management Academic Research Society (www.hrmars.com)

This article is published under the Creative Commons Attribution (CC BY 4.0) license. Anyone may reproduce, distribute, translate and create derivative works of this article (for both commercial and non-commercial purposes), subject to full attribution to the original publication and authors. The full terms of this license may be seen at: http://creativecommons.org/licences/by/4.0/legalcode

Vol. 8(4) 2019, Pg. 900 - 911

http://hrmars.com/index.php/pages/detail/IJARPED

JOURNAL HOMEPAGE

Full Terms \& Conditions of access and use can be found at http://hrmars.com/index.php/pages/detail/publication-ethics 


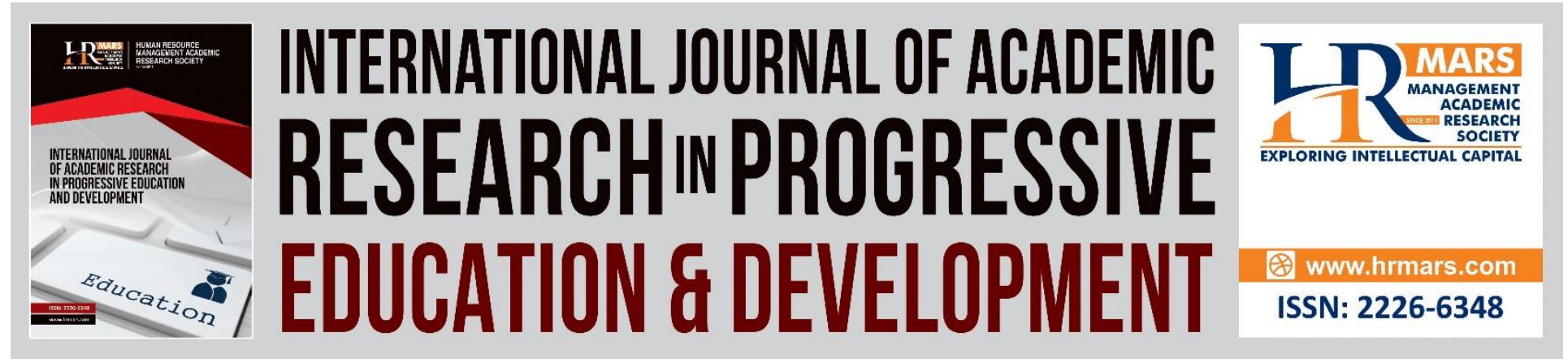

\title{
Potential Factors of Presenteeism: Job Demands, Work Engagement \& Job Insecurity
}

\author{
Daniella M. Mokhtar ${ }^{1}$, Mohd Syazwan Zainal², Mohd Haikal Anuar \\ Adnan $^{3}$ \\ ${ }^{1,3}$ Faculty of Social Sciences and Humanities, Universiti Kebangsaan Malaysia, ${ }^{2}$ Faculty of \\ Education, Universiti Kebangsaan Malaysia \\ Email: syazwanzainal@ukm.edu.my
}

\begin{abstract}
Presenteeism is a phenomenon that can potentially produce considerable risks for organizations. It had been researched that its negative outcomes are even greater than that of absenteeism. Therefore, the purpose of this cross-sectional study is to identify the potential factors that contribute to presenteeism, including job demand, work engagement, and perceived job insecurity as potential antecedents of presenteeism. Four hundred diplomatic officers were selected via convenient sampling from INTAN campus in Terengganu and Johor. They were given a set of self-report questionnaires containing the factors that were studied. The results of this study confirmed that presenteeism was significantly correlated with job demand $(r=.39, p<.05)$, work engagement $(r .=.29, p<.05)$ and a had negative significant relationship with perceived job insecurity $(r=-.07, p<.05)$. Findings from this study can serve as a baseline for more research to be conducted in efforts to build high impact interventions to minimize presenteeism. Further discussions on findings are reported in the article.

Keywords: Presenteeism, Job Demand, Work Engagement, Perceived Job Insecurity, Diplomatic Officers

\section{Introduction}

Attending work with poor health condition is just as though you are 'invisible'; being present at workplace but without contributing anything of value (Cooper, 1996). This phenomenon is known as presenteeism, which a condition where individuals go to work but do not perform, as they are supposed to be at home resting due to their illness or due to having spent too many hours working (Hemp, 2004). Presenteeism can be categorized into two categories - , those caused by acute sickness such as influenza or migraine, or those caused by chronic illness which have a longer term effect such as arthritis (Schultz, Chen \& Edington, 2009). According to Roe (2003), presenteeism may affect the organization negatively in two ways: individual impact and collective impact. Individual impact refers to the worker's performance.
\end{abstract}


Vol. 8, No. 4, 2019, E-ISSN: 2226-6348 @ 2019 HRMARS

The lack of performance is due to decreased work quality, not to mention the amount of extra time and effort an ill worker has to put in as compared to a healthy worker. More time at work means more effort invested and this leads to an imbalanced lifestyle which eventually causes the health to deteriorate (Matuyama, Kohno, \& Moriomoto, 1995). Matuyama, Kohno and Moriomoto (1995) explained that long working hours may expose the ill worker to unhealthy activities such as smoking or becoming the secondary smoker, having imbalanced diet and lacking exercise. Collective performance will also decline due to the distribution of help given to those who could not perform well given their state of health.

Workers who are healthy and can function well have to divide their time helping or substituting on behalf of the ill workers, and things could get worse when the sickness spread, resulting in the working environment being contaminated. According to a longitudinal study by Hofstede (1973) in the book Organizational Behavior written by Robbins and Judge (2013), Malaysia is ranked number 36 in a comparison of working style (individualistic versus collectivism) across 53 countries. Referring to the table provided in the book, Malaysia is categorized as a country prone to collectivism. Workers of this culture stress on a social framework whereby individuals tend to rely or depend on other group members to care or protect them in an organizational context (Hofstede, 1973).

Generally, individuals have the tendency to keep on working in spite of being ill as they believe most tasks are not to be procrastinated or passed on to another colleague (McKevitt, Morgan, Dundas, \& Holland, 1997). A research by Davis, Collins, Doty, Ho and Homgren (2005) found that half of their total number of respondents still came to work, even when some of them were having cardiovascular problems. Also, 56\% reported facing at least one of their working days with health problems which affected their work productivity (Davis et al., 2005). Around $62 \%$ of the working population in America were more concerned on completing their task even with a minimum effort, and $26 \%$ treated their attendance to work as the main objective. Apart from that, presenteeism could also be stimulated by increased pressure to complete or carry out certain task which eventually may also affect the company's productivity (Hinkle,1973; Manshor,et al and Chong, 2003).

Furthermore, relating to the loss borne by organizations, in reality, presenteeism causes more damage as compared to absenteeism (Hemp, 2004). Numerous researches has been carried out concerning the financial effects of presenteeism in an organization. For instance, a total cost of more than 150 billion dollars was spent per annum, as calculated by The American Productivity Audit. From that total cost, expenditure relating to presenteeism was twice or thrice the amount of direct health costs (Burton, Morrison \& Wertheimer, 2003). Loss pertaining to presenteeism does not only manifest in the form of money, but it also concerns work productivity. Levin-Epstein (2005) states that The Centre for Law and Social Policy reported a significant incline in terms of productivity loss when coming to work while sick, with a value of $72 \%$ compared to not coming at all, with just a $28 \%$ loss in productivity. 
Vol. 8, No. 4, 2019, E-ISSN: 2226-6348 @ 2019 HRMARS

Presenteeism may reflect the organizations' productivity losses in terms of work quality and the quantity of work managed to be completed as a result of poor health or injury which are often referred to as disabilities at the workplace (McKevitt, et al., 1997; Aronsson, et.al., 2000; Koopman, et al., 2002). This opinion is also parallel with Hemp's (2004) findings which found that working under poor health conditions will produce a negative impact towards both quantity and quality of the job. This is due to the lower pace performed by ill individuals and the lower precision due to lack of focus. Occupations that often experience this phenomenon include those working in the education sector, health sector and welfare agencies. Examples of occupations are teachers and nurses (Aronsson, Gustafsson, \& Dallner, 2000; Elstad \& Vabo, 2008; Bergstrom et al., 2009).

\section{Potential Correlates of Presenteeism}

Various reasons could be the cause of this phenomenon. One of them is job demand. Job demand involves effort either physically or psychologically that often corresponds with physical rewards such as bonus, pay increment or psychological rewards such as accreditation, promotion and praise (Rothmann \& Jordaan 2006). On top of that, the demands cover physical, psychological, social and emotional aspects. But in this study, the researcher will only touch on physical (workload) and psychological (emotional and cognitive) demands. "Things that I have to do", is another concept that briefly defines job demand according to Jones and Fletcher (1996). 'Things' refer to demands from the organization which includes aspects of physical, social or organizational demand that requires consistent effort in terms of physical and psychological aspects that include cognition and emotions. In addition, Demerouti, Bakker, Nachreiner, and Schaufeli (2001) suggest that job demand has a relationship with physiological and psychological effects.

According to another theory known as the COR theory (short for Conservation of Resources), job demands include workload, role ambiguity and stressful events (Hobfoll, 1998). When there is an increase in job demand, and resources are limited, the organization has the tendency to require resources from workers to meet the demand (Hofboll, 2001). In this study, the resources from workers refer to the psychological, emotional and cognitive context. According to Hofboll (2001), individuals tend to use a strategy known as resource conservation which is applied in a situation that threatens them. This strategy also acts as a coping mechanism that requires them to invest personal resources in order to fulfill the inconvenient demands. These personal resources also include time after work and extra energy and focus.

However, Koopman and friends (2002) opine that presenteeism may be due to being engaged at work. Work engagement may be defined as an investment in the form of specific emotional, cognitive and physical energy required to achieve high job performance (Kahn, 1990). It is deeper than work commitment as quoted by Robbins and Judge (2013) and is at the same time seen as a positive aspect which contradicts burnout (Schaufeli \& Salanova, 2007). Compared to those with high levels of burnout, individuals with high work engagement are more energetic and are capable in managing job demands well (Schauflli, Bakker, \& Salanova, 2006). As 
suggested by Maslach, Schaufeli and Leiter (2001), vigor and dedication (a sub-dimension of work engagement) directly oppose two dimensions of burnout, namely exhaustion and cynicism.

Work engagement closely relates to the positive state of mind which can be categorized into three sub-dimensions; vigour, dedication and absorption (Schaufeli, Salanova, GonzálezRomá, \& Bakker, 2002; Bakker \& Schaufeli, 2008; Schaufeli \& Salanova, 2007). Vigour refers to high level of energy and mental resilience while working, willingness to invest a certain amount of effort and remain hardworking throughout obstacles faced. Secondly, dedication requires important emotional experience, will, inspiration and pride in carrying out work-related tasks. The third sub-dimension, absorption, is the full concentration and attention given where individuals in this stateare immersed with their work and find it almost impossible to separate themselves from their job.

Perceived job insecurity appears to be related to individual's negative reaction (Cuyper \& Witte, 2005; Mauno, Leskinen \& Kinnunen, 2001). It may result in a negative impact either towards the individual, group or the organization itself. Focusing on the well-being of an employee, job insecurity has been said to lessen or cause the employee's well-being to deteriorate (Ashford et al., 1984). The negative part of it which includes anxiety, feeling or restlessness may result in presenteeism whereby insecure employees would be pressured to attend work regardless of his poor health; physically or psychologically. Employees who fear losing their job would be more motivated to engage at work as a response strategy to address the threat (Hirschman, 1970; Sverke \& Hellgren, 2002).

Employees may also have the impression of showing great effort to increase their performance and they might put in some sense of establishment and secure a stable position in the organization. Luthans and Youssef (2007) also said that workers who are worried about losing their jobs will respond by increasing their efforts to work hard and spend more time to complete their work. Hence, Mauno and his colleagues (2005) assumed that the higher the work engagement, the more secure they would feel and thus will experience job insecurity or threat on a smaller scale. This may suggest that working extra hours and working outside of the formal working parameters such as offices, work sites and job specifications may be due to perceived insecurity of their job.

\section{Research Methods \\ Design and Sample}

This study employed a cross-sectional survey on 400 diplomatic officers located in Terengganu and Johor. The final usable data was 292 samples after being filtered for missing data, outliers and unreturned questionnaires. Majority of the respondents were female (74.0\%), between the ages of 33 to 40 (80.1\%) Malay (89.7\%) and married (69.9\%). Instruments that were used consisted of validated scales that were adapted from previous research and had undergone backto-back translations. Respondents were briefed on the instructions and a method example was demonstrated to increase their understanding. Once finished, they were then asked to answer the questionnaires on their own without any time limit given. The respondents however did not 
Vol. 8, No. 4, 2019, E-ISSN: 2226-6348 ㄷ 2019 HRMARS

require more than 45 minutes, and they were allowed to ask questions during this process. In general, they did not face any difficulties in answering the questions as it was asked in layman terms and in simple sentences. Once completed, the questionnaires were collected by hand for further steps in analyzing the results

\section{Instruments}

Presenteeism. Presenteeism was measured using 6 items from the short version of the Standford Presenteeism Scale (SPS-6) developed by Koopman and his colleagues (2002). The scale involved two dimensions, namely work completion ( 3 items) and distraction avoidance ( 3 items). All items were positive, and responses were based on a 5-Likert scale ranging from (1) Strongly Disagree to (5) Strongly Agree. An example of the items is "Even though I have health problems, I was able to complete the tasks in the workplace". The reliability value of the scale was relatively high, $\alpha=$ .75 .

Job Demand. Job demand was measured using 19 items; 5 items adapted from the Job Content Questionnaire (JCQ) developed by Karasek and his colleagues (1985) and 14 items were adapted from the Experience and Evaluation of Work questionnaire by Veldhoven Mejimen (1994). The scale involved three dimensions which are workload (5 items), emotional ( 7 items) and cognitive demands (7 items). All items were positive, and responses were based on a 4-Likert scale ranging from (1) Strongly Disagree, to (4) Agree. An example of the items is "Do you have a lot of emotional work requests". The reliability value of the scale was relatively high, $\alpha=.72$.

Work Engagement. Work engagement was measured using 9 items from the Utrecht Work Engagement Scale (UWES) by Schaufeli and Bakker (2003). The scale involved three dimensions which are vigor ( 3 items), dedication ( 3 items) and absorption ( 3 items). All items were positive, and responses were based on a 7-Likert scale ranging from (0) Never to (6) Always. An example of the items is "I am very passionate of my work". The reliability value of the scale was relatively high, $\alpha=.76$.

Perceived Job Insecurity. Perceived job insecurity was measured using 18 items from the Job Insecurity Scale (JIS) by Ashford and his colleagues (1989). The scale involved two dimensions which are importance ( 9 items) and probability ( 9 items). All items were positive, and responses were based on a 5-Likert scale ranging from (1) Highly Unimportant, to (5) Highly Important. An example of the items is "You may lose your job or be moved to a lower level at work". The reliability value of the scale was relatively high, $\alpha=.73$.

\section{Analysis}

Analysis was performed using the Statistical Packages for Social Sciences (SPSS) Software. Descriptive analysis was performed to look at frequencies and descriptive values while inferential statistics were used to look at correlational values between the variables in the study. 
INTERNATIONAL JOURNAL OF ACADEMIC RESEARCH IN PROGRESSIVE EDUCATION AND

DEVELOPMENT

Vol. 8, No. 4, 2019, E-ISSN: 2226-6348 @ 2019 HRMARS

\section{Findings}

The table describes the frequency of each variable used in this study which are presenteeism, work engagement, job demand and job insecurity. All four variables were categorized with three levels: low, moderate and high. The results are shown in the table below: -

Table 1: Frequency Levels of the Variables

\begin{tabular}{lccc}
\hline VARIABLE & LEVEL & FREQUENCY & PERCENTAGE (\%) \\
\hline Presenteeism & Low & 4 & 1.4 \\
& Moderate & 194 & 66.4 \\
& High & 94 & 32.2 \\
Work Engagement & Low & 1 & .3 \\
& Moderate & 172 & 58.9 \\
& High & 119 & 40.8 \\
Job Demand & Low & 25 & 8.6 \\
& Moderate & 247 & 84.6 \\
& High & 20 & 6.8 \\
Job Insecurity & Low & 12 & 4.1 \\
& Moderate & 216 & 74.0 \\
& High & 64 & 21.9 \\
TOTAL & & 292 & 100 \\
\hline
\end{tabular}

Table 1 displays the frequency level of the four variables studied in this research. Respondents were reported with majority having moderate to high level of presenteeism whereby 194 respondents (66.4\%) were moderate and 94 respondents (32.2\%) were high with presenteeism, leaving only 4 respondents (1.4\%) with low frequency of presenteeism. Meanwhile, the report for work engagement shows that 172 respondents (58.9\%) were moderately engaged or in this case, dedicated. Only 119 (40.8\%) of them were absorbed in their work while only one repsondent $(0.3 \%)$ had low engagement with work. In terms of job demand, majority of the samples had moderate demands from their job (247 respondents, 84.6\%). A total of 20 respondents (6.8\%) had high job demands and 25 respondents (8.6\%) had low demands. Lastly, 216 repsondents $(74.0 \%)$ was moderately insecure with their jobs whilst 64 repondents $(21.9 \%)$ had perceived high insecurity and only 12 (4.1\%) of them had low job insecurity.Table 2 presents the result of the Pearson correlation that was used to test the relationship between presenteeism, job demand, work engagement and perceived job insecurity. 
Vol. 8, No. 4, 2019, E-ISSN: 2226-6348 @ 2019 HRMARS

Table 2: Correlations between study variables

\begin{tabular}{lcccc}
\hline Dimension & $\mathbf{1}$ & $\mathbf{2}$ & $\mathbf{3}$ & $\mathbf{4}$ \\
\hline 1. Presenteeism & - & & & \\
2. Job Demand & $0.39 *$ & - & & \\
3. Work Engagement & $0.29 * *$ & 0.23 & - & \\
4. Perceived Job Insecurity & $-.07^{*}$ & $-.11^{*}$ & .032 & - \\
\hline
\end{tabular}

Table 2 displays the correlation values between the four variables observed in this study. Results show that there is a positive significant relationship between presenteeism and job demand $(r=$ $.39, p<.05)$, work engagement $(r .=.29, p<.05)$ and a negative significant relationship with perceived job insecurity $(r=-.07, p<.05)$. These results suggest that higher job demand and work engagement result in higher tendency of employees to be involved in presenteeism. Meanwhile, this result also suggests that samples in this study lessen engagement in presenteeism when they perceive job insecurity.

\section{Discussion}

The relationship found between job demand and presenteeism was aligned with previous studies (Hockey, 1993; Demerouti et al., 2005; Demerouti, Le Blanc, Bakker, Schaufeli, \& Hox, 2009). Previous studies found that protecting their reputation or maintaining a proper level of performance may be the reason why they are still present at work though ill or fatigued. Somehow, the demand creates a form of stress which pushes the employees to still be present. Job demands closely relates to a sustained effort, either physically or psychologically, which then produces certain costs (Demerouti et al., 2001). They do not usually stand in the negative group as it can be something that encourages or stimulates productivity of a person. Nevertheless, when extra efforts are needed, that is when the job demands can turn intro stressors especially when there are limited resources, similar to what was proposed by Meijman and Mulder (1998).

The conservation of resources theory by Hofboll (1989) may also be applied here, where employees strive to retain or maintain what they value, in this case could be their performance and reputation at work. By putting in tremendous effort which can be exhausting, it may cause a negative impact towards their health, but nevertheless, by reasoning based on this theory, the employee would still proceed to work to meet the high demands and to maintain his performance that earns him a good reputation. Similar findings were found for the relationship of work engagement and presenteeism. This finding is consistent with several past researches, for instance, the research on engagement and presenteeism among NHS staff that was carried out in the year 2011. Their study found that work engagement was related to presenteeism provided demographic and job characteristics were taken into account (Admasachew, L. \& Dawson, J, 2011). However it may be explained by people being 'engaged' due to feelings of insecurity. From an employee's point of view, being absent will just cause him loss in terms of pay or even attendance allowance. So why not be present just for the sake of a full attendance? Being sick or unable to concentrate is a different matter. What is more important is that they do 
Vol. 8, No. 4, 2019, E-ISSN: 2226-6348 @ 2019 HRMARS

not lose out in their participation, albeit it is ineffectual or even detrimental, not only to the individual but to the organization as well.

In terms of perceived job insecurity, results showed that whether an employee was worried or felt insecure or vice versa concerning his job, it did not lead to accurate prediction of the presenteeism phenomenon. The assumption was that when a person feels unsure of his stability in a job or feels threatened by the probability of him being demoted or transferred, he will have the tendency to try to make things right. And for making things right, being absent is not an option. So rather than applying for sick leave, they would prefer to attend to work so that the attendance record would not be affected. Most employees would have the thinking that not showing up to work will make things worse and would increase the threat perceived. According to Ashford et al. (1984), the feeling of insecurity will just worsen the person's wellbeing. For instance, a sick employee who is worried of losing his job will continue to be present at work, not realizing that his sickness may not improve but instead, get worse. What is even worse is when his sickness infects the other employees and consequently incurs higher losses to the organization.

However, results obtained showed no association between job insecurity and presenteeism. This relates back to the stability of the position as a diplomatic officer where government jobs are usually guaranteed and the tendency to associate with presenteeism is quite low due to the perceived security as a government officer. Apart from that, the organization policies could also contribute towards the feeling of security where rules and regulations were laid out clearly for the employees to understand. A possible explanation is that the employee does not have to worry about his future with the organization and thus resulting in him not having to force himself to work whenever he falls sick.

\section{Conclusion}

The results of the study showed that job demand and work engagement have effects towards presenteeism. These findings can be a stepping stone for further research in organizations, and not just in the government sector, to review issues faced by employees. As for the private sector, though research was carried out only in the government sector, they could make this as a guide and arrange appropriate measures to prevent from a significant loss in terms of costs and productivity due to presenteeism. The workload of the job should be bearable and should not overburden the employees. A proper dateline should be arranged by the employers with sufficient time frame for the employees to complete a task especially when they are sick. Employers should allow them to take a break; productivity could increase appreciably once the sick employee gets better. Organizations should also not propagate feeling of insecurity among employees as this will only lessen productivity. When instilled with insecurity, the employees may be compelled to show up to work, but the quality of their work would be highly suspect.

The results obtained, it is hoped, would alert employers on the seriousness of this issue and the factors that could really contribute to presenteeism. By giving attention to this matter and by giving it due attention, it may well bring beneficial outcomes to the company. This is by 
means of early detection of this behavior, and organizations would be able to form a special team to handle this matter. Interventions could also help in this issue and the results of this study could be empirical evidence that could lead to the development of an intervention protocol. Though it (presenteeism) may not be totally eradicated, it could bring a significant change to the organization in terms of costs and work productivity. These measures are considered crucial as the employees are actually those running the organization.

This study has the potential to increase awareness of employees as well on the effects of insecurity towards presenteeism. With that, in order to achieve the vision and mission, the employees together with the organization must work together to attain great heights. Nevertheless, a more definite conceptual framework would be needed, and this may be acquired from researches on presenteeism that are rapidly evolving. Studies related to presenteeism had similar findings though the differences were in terms of magnitude and the relationship strength. This is due to the adaptiveness element which in turn, depends on individual differences and cultures which this study did not address. Therefore, this may be one of the research gaps that could act as a baseline for this particular research in the future.

\section{Acknowledgement}

This project was supported by the Faculty of Education, Universiti Kebangsaan Malaysia grant GG-2019-003.

\section{References}

Aronsson, G., Gustafsson, K., Dallner, M. (2000). Sick but yet at work. An empirical study of sickness presenteeism. Journal of Epidemiol Community Health 54:502-509

Hemp, P. (2004). "Presenteeism: at work - but out of it", Harvard Business Online, October.

Johns, G. (2010). Presenteeism in the workplace: A review and research agenda. Journal of Organizational Behavior 31: 519-542

Beaton, D., Bombardier, C., Escorpizo, R., Zhang, W., Lacaille, D., Boonen, A. (2009). Measuring worker productivity: frameworks and measures. Journal of Rheumatol 6: 2100-2109

Bergström, G., Bodin, L., Hagberg, J., Lindh, T., Aronsson, G., \& Josephson, M. (2009). Does sickness presenteeism have an impact on future general health? International Archives Environmental Health 82: 1179-1190

Demerouti, E., Blanc, L. P. M., Bakker, A. B., Schaufeli, W. B., \& Hox, J. (2009). Present but sick: A three-wave study on job demands, presenteeism and burnout. Career Development International, 14: 50-68.

Elstad, J. I., \& Vabo, M. (2008). Job stress, sickness absence and sickness presenteeism in Nordic elderly care. Scandinavian Journal of Public Health 36:467-474.

Fox, M., Dwyer, D., \& Ganster, D. (1993). Effects of stressful job demands and control on physiological and attitudinal outcomes in a hospital setting. Academy of Management Journal 36(2): 289-318.

Garst, H., Frese, M., \& Molenaar, P. C. M. (2000). The temporal factor of change in stressor strain relationships: A growth curve model on a longitudinal study in East Germany. Journal of Applied Psychology 85: 417-438 


\section{DEVELOPMENT}

Vol. 8, No. 4, 2019, E-ISSN: 2226-6348 ㄷ 2019 HRMARS

Greenhalgh, L., and Rosenblatt, Z. (1984). Job insecurity: Toward conceptual clarity. Academy of Management Review 3: 438-448

Hirschman, A. (1970). Exit, Voice and Loyalty: Responses to Decline in Firms, Organizations and States. Harvard University Press. UK: Cambridge

Hobfoll, S. E. (1998). The psychology and philosophy and stress, culture, and community. NewYork:Plenum Books.

Kahn, W. A. (1990). Psychological Conditions of Personal Engagement and Disengagement at Work. Academy of Management Journal 33(4): 692-724

Koopman, C., Pelletier, K. R., Murray, J. F., Sharda, C. E., Berger, M. L., \& Turpin, R. S. (2002). Stanford presenteeism scale: health status and employee productivity. Journal of Occupational Environment Medicine 44: 14-20

Luthans, F., \& Youssef, C. M. (2007). Emerging positive organizational behavior. Journal of Management 33: 321-349

Maruyama, S., Kohno, K., \& Morimoto, K. (1995). Effects of long working hours on lifestyles, perceived stress and working-life satisfaction among white-collar middle-management employees. Japanese Journal of Hygiene 50: 849-860

Maslach, C., Schaufeli, W. B., \& Leiter, M. P. (2001). Job burnout. In S. T. Fiske, D. L. Schacter, \& C. Zahn-Waxler (Eds.), Annual Review of Psychology 52: 397-422

Mauno, S., Kinnunen, U., Mäkikangas, A. (2005). Psychological consequences of fixed term employment and perceived job insecurity among health care staff. European Journal of Work and Organizational Psychology 14(3): 209-237.

May, D. R., Gilson, R. L., and Harter, L. M. (2004). The psychological conditions of meaningfulness, safety and availability and the engagement of the human spirit at work. Journal of Occupational and Organizational Psychology 77: 11-37.

McClelland, D. C., \& Burnham, D. H. (1976). Power is the great motivator. Harvard Business Review 54(2): 100-110

McDonal, D. J. \& Makin, P. J. (2000). The psychological contract, organizational commitment and job satisfaction of temporary staff. Leadership and Organization Development Journal 21(2): 84-91

McKevitt, C., Morgan, M., Dundas R, Holland, W. W. (1997). Sickness absence and 'working through'illness: a comparison of two professional groups. Journal of Public Health Medicine 19: 295-300

Meyer, J. P., \& Parfyonova, N. M. (2010). Normative commitment in the workplace: A theoretical analysis and re-conceptualization. Human Resources Management Review 20: 283-294

Probst, T. M. (2003). Development and validation of the job security index and the job security satisfaction scale: a classical test theory and IRT approach, Journal of Occupational Psychology 76: 451-467

Rafferty, A. E., \& Griffin, M. A. (2006). Perceptions of organizational change: A stress and coping perspective. The Journal of Applied Psychology 91(5): 1154-1162.

Rosenblatt, Z, \& Ruvio, A. (1996). A test of a multidimensional model of job insecurity: The case of Israeli teachers. Journal of Organisational Behavior 17: 587-605.

Saks, A. M. (2006). Antecedents and consequences of employee engagement, Journal of Managerial Psychology 21(6):600-619. 
Saks, A. M. (2008). "The meaning and bleeding of employee engagement: How muddy is the water?" Industrial and Organizational Psychology, 1: 40-43.

Sverke, M., Hellgren, J., \& Nawall, K. (2006). Job Insecurity: A literature review. National Institute for Working Life 1: 1-23

Sverke, M., \& Hellgren, J. (2002). 'The Nature of Job Insecurity' Understandi Employment Uncertainty on the Brink of a New Millennium'. Applied Psychology: An International Review 51(1): 23-42.

Sverke, M., Hellgren, J., \& Näswall, K. (2002). No security: A meta-analysis and review of job insecurity and its consequences. Journal of Occupational Health Psychology, 7: 242-264

Vuuren, V. T. (1990). Threatened with dismissal: Employees uncertainty about their jobs with changes in the organization. Amsterdam: VU University Press. 